\title{
Huellas Olvidadas de los Refugiados Hebreos en Cuba durante la Segunda Guerra Mundial
}

\author{
Forgotten Footprints of the Hebrew \\ Refugees in Cuba during World War II
}

\author{
Adriana Hernández Gómez de Molina \\ Colegio Universitario San Gerónimo de \\ La Habana. Universidad de La Habana, \\ Cuba
}

\section{Resumen}

La presente disertación aborda la llegada a Cuba de las diferentes oleadas migratorias de hebreos en la primera mitad del siglo XX. Sobre todo, se centra en la cuarta y última oleada de los judíos refugiados (1933-1948), que huían del nazismo ante el ascenso de Hitler al poder en Alemania y la posterior expansión del Tercer Reich por Europa Occidental, y el desenvolvimiento de la Segunda Guerra Mundial. De tal modo que la misma, se adentra en las características de esta migración, sus tendencias asociativas y las estrategias de adaptación utilizadas, así como su relación con la comunidad hebrea residente, para enfocarse en las huellas de su paso por la Isla a través de tres experiencias poco tratadas en la historiografía: la creación de la industria del diamante, la experiencia de ayuda interdenominacional en la finca "Paso Seco", y sus huellas en el cine cubano.

Palabras Claves: Migraciones, hebreos, refugiados, huellas, experiencias.

\begin{abstract}
The presentation addresses the arrival in Cuba of the different migratory waves of Jews in the first half of the 2oth century, especially the fourth and last wave of the so-called "refugees" (1933-1948), Jews who fled Nazism from Hitler's rise to power in Germany and the subsequent expansion of the Third Reich into Western Europe and the unfolding of World War II. It push forward into the characteristics of this migratory wave, its associative tendencies and adaptation strategies of the refugees, as well as their relationship with the host Cuban Jewish community, to focusses on the traces of their passage through the Island through three little-discussed experiences in historiography: the training of the diamond industry, the interdominational aid experience of "Paso Seco" property and its traces in Cuban cinema.
\end{abstract}

Keywords: Migrations, Hebrews, refugees, footprints, experiences.

\section{La inmigración hebrea a Cuba}

Aunque la mayoría de los investigadores coinciden en que la presencia hebrea en Cuba data del mismo momento en que Cristóbal Colón descendió de sus naves, y con él un grupo de "conversos" que lo acompañaban (Koehler, 1943, p. 11; Matterin, 1969, p. 2; Ortiz, 1957, pp. 7-11), lo cierto es que esta empieza a hacerse claramente visible a partir de 1898 con la guerra hispano-estadounidense. Precisamente, cuando algunos soldados de origen judío, pero nacionalizados estadounidenses, y abastecedores del ejército de Teodoro Roosevelt decidieron quedarse en la Isla una vez finalizada la contienda; grupo inicial al cual luego se sumaron otros, atraídos por las posibilidades económicas que ofrecía la recién inaugurada república.

Posteriormente, los eventos que sacudieron al entonces Imperio Turco Otomano como la Revolución de los "Jóvenes Turcos" (1908), las Guerras Balcánicas de 1912-1913, y la Gran Guerra de 1914 arroja- ron a las costas cubanas a los sefardíes (Hernández Gómez de Molina, 2019a): judíos provenientes de la cuenca mediterránea que huían del servicio militar y a quienes la guerra, que tantos sufrimientos ocasionaba en sus lugares de origen, favoreció en la Isla con nuevas posibilidades económicas derivadas de la expansión de la industria azucarera durante la llamada "danza de los millones", propiciada por el alza de los precios del azúcar en el mercado mundial. Durante este período se elevó el nivel adquisitivo de la población cubana, y los inmigrantes sefardíes, que se dispersaron por la Isla como vendedores ambulantes, fueron recibidos por una población ávida de adquirir sus mercaderías.

Para la década del 20 arribaron los judíos asquenazíes (Hernández Gómez de Molina, 2019b), procedentes de la Europa del Este -fundamentalmente de Polonia, Lituania y Rusia-; impelidos por las políticas nacionales respecto a las minorías tras la Primera Guerra Mundial y por los pogromos acontecidos 
en la región tras la revolución rusa de 1917 (Bejarano, 1996), pero sobre todo, por la imposibilidad de llegar a su destino de elección -los Estados Unidos de América- en virtud de las restricciones migratorias norteamericanas entre 1921 y 1924, también conocidas como "leyes de cuotas". En este caso, el congreso norteamericano, primero limitó el número de inmigrantes a una "cuota" anual de 3 por ciento de la población de cada nacionalidad existente en el territorio de los Estados Unidos en el año 1910, toda vez que facilitaba la entrada libre de inmigrantes con al menos un año de residencia en algún país latinoamericano. Sin embargo, finalmente recrudeció las restricciones en 1924, al reducir la cuota anual al 2 por ciento de oriundos de cada país en relación a la población existente de ese origen en 1890, anulando así el privilegio de entrar fuera de la cuota otorgado anteriormente a inmigrantes ya establecidos en alguna nación latinoamericana (Bejarano, 1996).

Posteriormente, los eventos sucedidos en Europa por el ascenso del fascismo en la década de 1930, y acelerados por la guerra civil española, tanto como por el avance del nazismo en Europa occidental a partir de 1939, trajeron a los refugiados judíos, los cuales fueron desplazados consecutivamente desde 1933 hasta 1948. Sobre esta última oleada migratoria de judíos a Cuba -tanto de los refugiados del fascismo, como de los sobrevivientes del Holocausto- y sobre las huellas de su paso por la Isla, es que versará esta reflexión histórica.

\section{Los refugiados y su llegada a Cuba}

Los refugiados eran un grupo mixto procedente de Europa occidental (en su mayoría de Alemania, Austria y Bélgica), compuesto básicamente por empresarios e intelectuales de las clases medias o medias altas. "Convertidos" en untermenschen (subhumanos) o "basura humana" (Levine, 1993, p. 79) por las políticas de "arianización" nazis después de las leyes de Nuremberg (1935), del Anschluss de Austria (1938), de la incorporación del protectorado de Bohemia-Moravia (1939) y de la ocupación de Francia, Bélgica y Holanda (1940). Atrás dejaban dinero, prósperos negocios, empleos profesionales y, lo más doloroso, familiares que quizás nunca volverían a ver.

Los judíos de Alemania y Austria que llegaron a Cuba en 1938 y 1939 no pensaban radicarse en el país, sino que buscaban un refugio transitorio hasta poder emigrar a los Estados Unidos. Las leyes cubanas en aquella época no favorecían la inmigración, privilegiando la defensa de los derechos de trabajo de la población nativa. Con todo y ello, la entrada de los refugiados se hizo posible por la venta de "permisos" -documentos firmados por el director del Departamento de Inmigración-, que facilitaban la entrada temporaria de los refugiados con la condición de que no trabajaran y de que no se convirtieran en una carga pública.

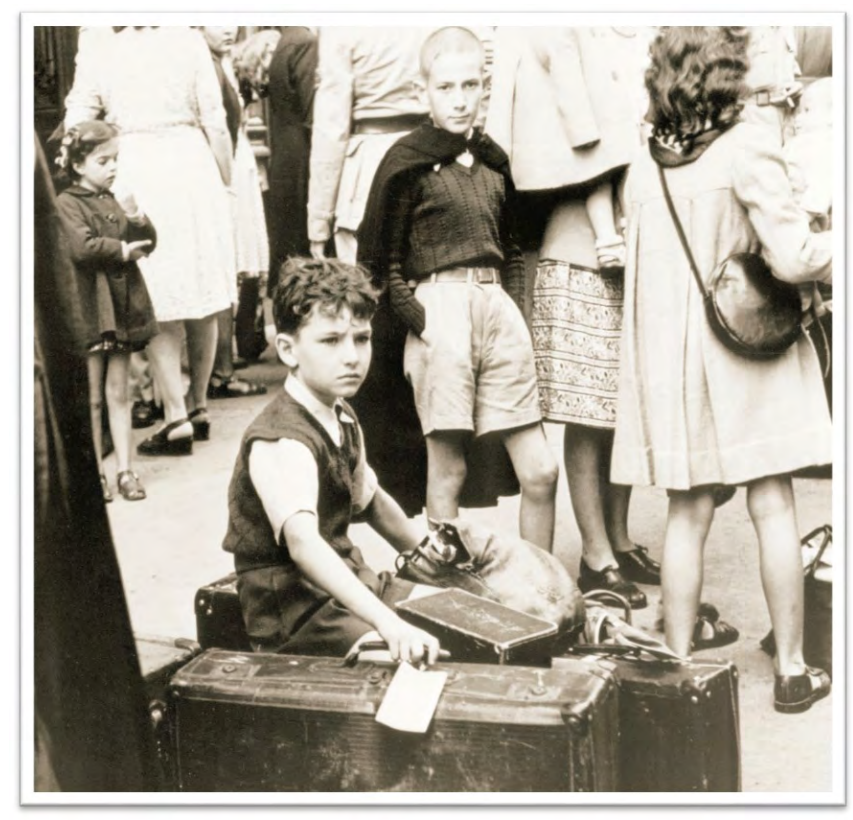

Figura 1. Refugiados europeos del nazi fascismo. Tomado de la exposición "Nosotros recordamos" Centro Hebreo Sefaradí de Cuba, La Habana 2005.

El 27 de mayo de 1939 arribó al puerto de La Habana el buque St. Louis, de la línea naviera alemana Hamburg Amerika Line, con 936 pasajeros judíos a bordo, a los cuales se les negó el permiso de desembarco, conforme al nuevo decreto de inmigración (Decreto 937) del 5 de mayo de 1939 emitido por el presidente Laredo Brú. Este, establecía la necesidad de que todo extranjero que pretendiera entrar al país, requería, además de una fianza por valor de 500 pesos, una visa expedida por las oficinas consulares en Europa con una triple aprobación por parte de la Secretaría de Estado, la Secretaría del Trabajo y la Dirección General de Inmigración, la cual, además, debía ser comunicada, directamente y por escrito, por esos funcionarios a las empresas de transporte, con anterioridad al embarque en el puerto de origen.

La tragedia del St. Louis puso a Cuba en el centro del problema en torno a los refugiados durante la Segunda Guerra Mundial y se convirtió en el símbolo de la actitud del mundo libre hacia los refugiados judíos en la época del Holocausto. Principalmente, 
por todo lo que supuso: la angustiosa espera en la rada habanera hasta la definitiva negativa de desembarco a sus tripulantes (los testimonios fotográficos son ilustrativos de lo que se dice, véase la Figura 1); la salida del puerto custodiado por la Marina de Guerra, en un peregrinaje a "velocidad crucero" por el Caribe, en espera de una solución de última hora, que no pudo ser hallada en toda la América; $y$, finalmente, el hecho de tener que enfilar proa de regreso a Alemania. No obstante, en Cuba hallaron refugio alrededor de 11000 judíos, la mitad de ellos antes de mayo de 1939, y la otra mitad en el período álgido de la guerra, esto es, entre octubre de 1940 y abril de 1942 (Bejarano, 1999, p. 3).

\section{Patrones asociativos}

Una vez en la Isla, los refugiados se establecieron mayormente en la capital y sus patrones de asociatividad se rigieron por sus lugares de origen, más que por su confesión judaica, ya que existían profundas diferencias de tradiciones religiosas, de idioma y de clase social entre los recién llegados y la comunidad hebrea cubana compuesta básicamente por sefardíes levantinos y asquenazíes de Europa oriental. Los refugiados se identificaron más con la comunidad hebrea norteamericana que, como ellos, era de origen asquenazí y sus miembros pertenecían a las clases acomodadas.

Por otra parte, como apuntó Robert Levine, la colectividad hebrea de Cuba en la primera mitad del siglo XX distaba mucho de ser homogénea y "sus miembros muchas veces se veían a sí mismos como sefardíes o asquenazíes, yiddish parlantes o "americanos», «alemanes» o «belgas» y aun desde pequeños subgrupos derivados de estas categorías" (Levine, 1993, p. 4). Así, los refugiados tendieron a asociarse por sus lugares de procedencia, existiendo diferentes asociaciones, por citar algunas: la Asociación Democrática de Refugiados Hebreos (integrada por germano-parlantes), la Unión de Refugiados Hebreos (integrada por belgas) (Archivo Nacional de Cuba y Fondo Registro de Asociaciones, L: 350; Exp.: 444), la Asociación de Hebreos Naturales de Lituania, la de Naturales de Varsovia, y la Asociación Hebrea de Oriundos de Pouzana. Un ejemplo de las directivas de estas organizaciones puede verse en la Figura 2. De todos los grupos de refugiados, los que más se acercaron a la colonia hebrea cubana sobre todo al grupo asquenazí de Europa del Estefueron los belgas, quienes, por sus raíces europeas orientales, ${ }^{1}$ su experiencia sionista previa, y en tanto portadores de una nueva industria en tiempos de guerra -la del diamante-, lograron darle un empuje renovador a la economía y al movimiento sionista de los hebreos cubanos.

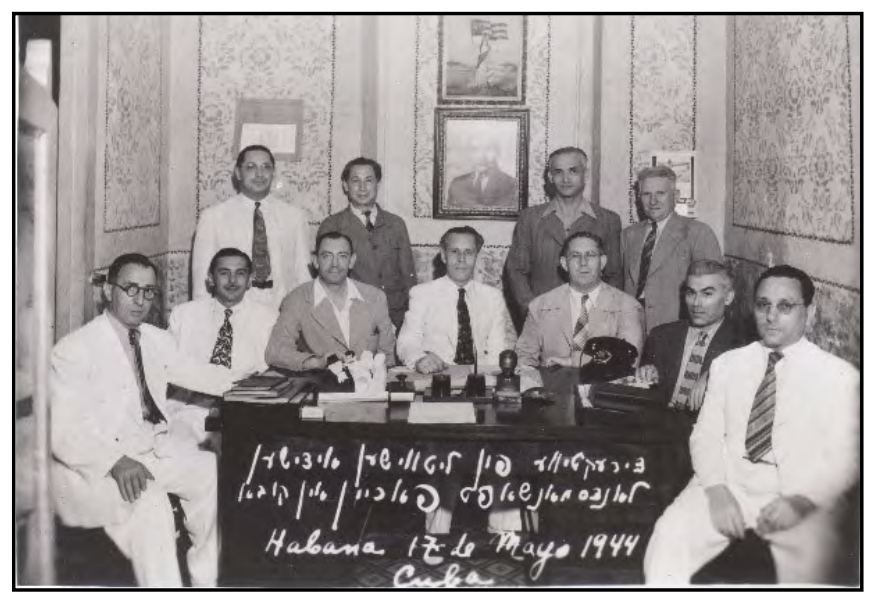

Figura 2. Directiva de la Asociación Oriundos de Lituania, 1944. Tomado de Bejarano, 1996. (Cortesía de Yad Vashem, Jerusalén).

\section{La comunidad receptora ante los refugiados}

En cuanto a la comunidad hebreo cubana residente, la misma estaba formada mayormente por inmigrantes de Europa del Este (Astro, 2002, p. 195). Los cuales habían arribado a Cuba durante el auge migratorio de la década de 1920. Como bien señala Perelmuter (2015), estos se encontraban en pleno proceso de adaptación y consolidación, razones por las cuales no hubo mucho entendimiento con los recién llegados.

La colonia hebrea en Cuba no contaba aún con posiciones económicas lo suficientemente sólidas, ni con la unidad interna necesaria para asumir un compromiso pleno con los recién llegados, que por demás provenían de las clases medias-altas europeas, con un nivel de conocimiento y cultura generalmente superior al de la mayoría de los hebreos cubanos. Según lo indica Hernández Gómez de Molina (2019c, p. 219), los judíos cubanos eran obreros y artesanos no calificados; hombres de las aldeas (Shetl), o del proletariado y de la pequeña burguesía urbana de Europa oriental. Por otra parte, los refugiados estaban legalmente imposibilitados de realizar cualquier trabajo por su condición de pasajeros de tránsito en espera de visas de entrada a los Estados Unidos, por lo que la responsabilidad de su manutención, más allá de algún que otro esfuerzo aislado de la colonia cubana, fue asumida básicamente por las organizaciones de ayuda norteamericanas con filiales en La Habana como el Jewish Relif Committee (JOINT) y Hebrew Immigrant Aid Society (HIAS). 
A propósito de cuanto se viene comentando, es ilustrativo el testimonio que recoge Margalit Bejarano (1996) de Lotte Berg, una alemana pasajera del Sao Tomé, último barco de refugiados que arribara a la isla coincidiendo con el cierre migratorio de 1942. Para entonces, el presidente Batista prohibió la entrada de "individuos de países enemigos", pero al mismo tiempo, otorgó el permiso legal de residencia mientras durara la guerra a los refugiados que se encontraban en la Isla. Comenta Berg: "Los representantes del JOINT nos ayudaban [...], no recuerdo haber visto a los representantes de la comunidad judía de Cuba en Tiscornia”.

\section{Los refugiados y su adaptación}

Para la gran mayoría debe haber sido una sensación extraña “... caminar por las calles atestadas de gente ruidosa...vendedores cantando su pregón... negros... mulatas.... La impresionante belleza de la arquitectura, especialmente, el Capitolio y el Malecón...", según se infiere del testimonio del médico vienés Adolph Mechener, citado por Levine (1993, p. 84). Para otros, “...habiendo vivido la mitad de mi vida bajo el régimen nazi... La Habana fue un lugar libre y glorioso" (Levine, 1993, p. 160). Asimismo, no faltaron los que, desorientados y apartados de sus seres queridos, no cesaban de comentar con amargura que en Alemania "todo era más eficiente...y civilizado” (Levine, 1993, p. 156).

Algunos refugiados compartían pensiones en antiguas casonas de la Habana Vieja con un patio central y pequeños apartamentos, bajo la "distancia amistosa y mirada benevolente" de sus vecinos cubanos, como testificó Ilsa Mitttel Ash, refugiada alemana que arribó a Cuba a bordo del Orinoco (Levine, 1993, p. 158). Otros -los más afortunados- ayudados por sus parientes de Estados Unidos, rentaban confortables apartamentos en el Vedado, provocando la envidia de los judíos "naturales" quienes observaban con disgusto como muchos de los recién llegados alcanzaban un nivel de vida superior a muchos hebreos cubanos (Levine, 1993, p. 159). Un reflejo de lo que se viene comentando puede observarse en la Figura 3. A todos, les molestaba el calor del trópico, la ropa que habían traído de Europa les provocaba sarpullido, y como la mayoría estaban legalmente impedidos de ejercer cualquier trabajo y tenía mucho tiempo libre, lo resolvieron yendo frecuentemente a la playa, aún en meses de invierno, cuando ningún cubano osaba hacerlo.

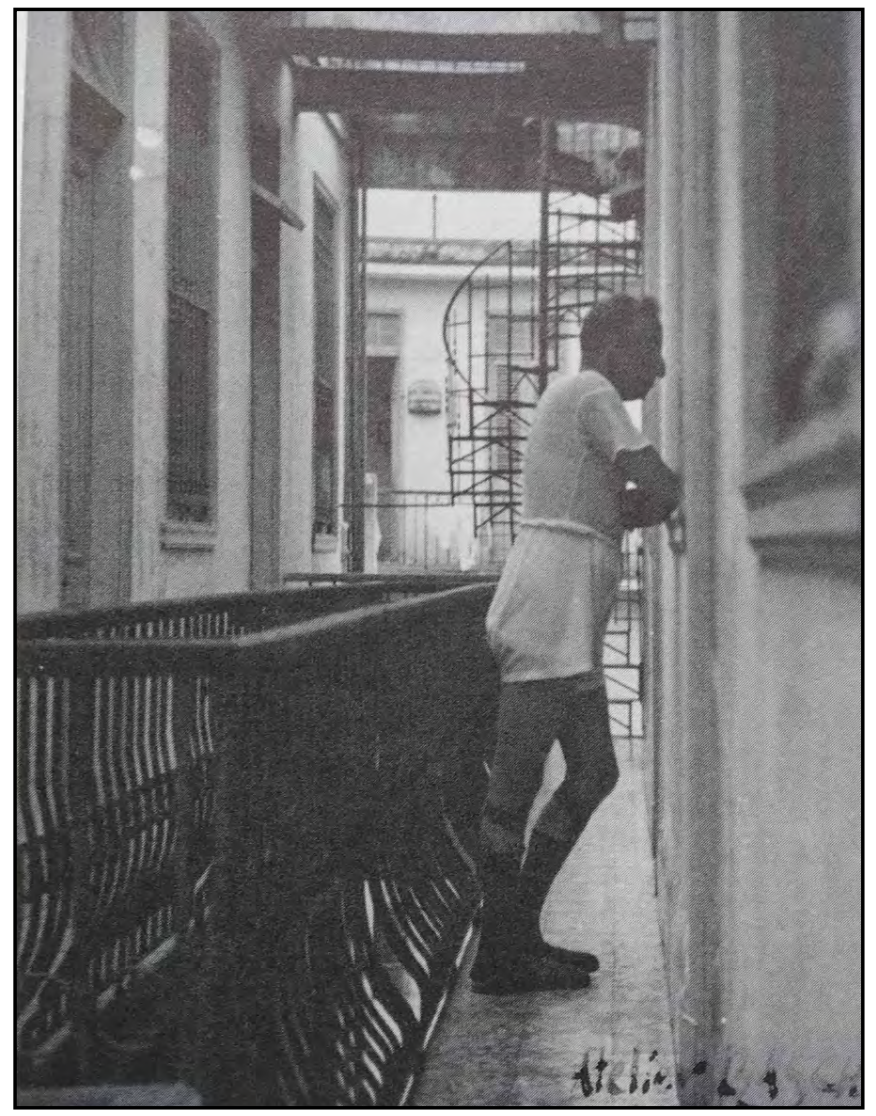

Figura 3. Refugiado alemán en el balcón de una casona habanera con patio central, 1940. Tomado de Robert Levine (1993). Cortesía de Norbert Adler.

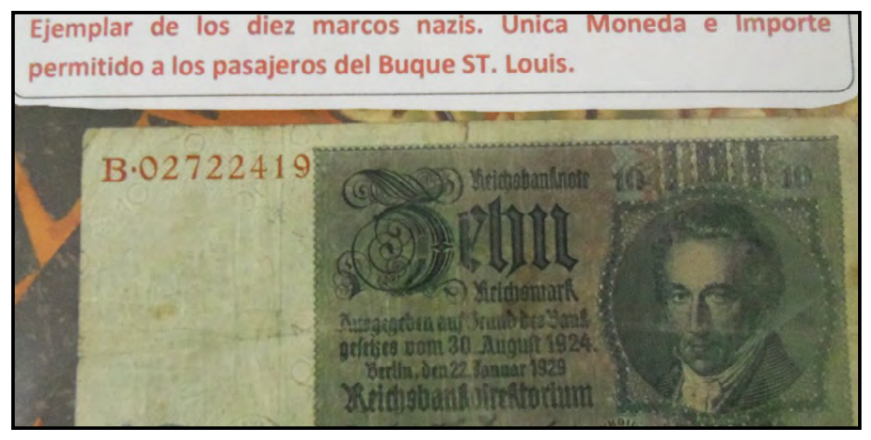

Figura 4. Ejemplar de 10 marcos nazis. Única moneda permitida a los pasajeros del buque de refugiados St. Louis. (Cortesía del Centro Sefaradí de Cuba).

Aunque impedidos legalmente de trabajar, hubo quienes evadieron las leyes para obtener algunos ingresos más allá de la ayuda que le suministraban las organizaciones filantrópicas norteamericanas. Las mujeres se pusieron a dar clases de piano, otros, de alemán, y algunos, como el doctor Adolph Mechener, aprovechaba sus conocimientos profesionales consultando discretamente a pacientes por 1 o 2 dólares entre sus mismos compatriotas (Levine, 1993, p. 84). En la Figura 4 puede verse un ejemplar de 10 marcos, que era la única moneda permitida a los pasajeros del Saint Louis. Hubo, incluso, quienes, gracias a 
pequeños sobornos, encontraron trabajo como vendedores, sobre todo en el interior del país. Otros por su parte se vincularon a los programas de la Agencia Judía de Servicio Social (ORT), recibiendo cursos de inglés y de oficios con vistas a prepararlos para su futuro viaje hacia los Estados Unidos. Del mismo modo, el grupo de los belgas crearon, bajo la mirada permisiva de las autoridades cubanas, una nueva industria hasta ese momento desconocida en Cuba.

\section{Tres experiencias olvidadas de los refugiados hebreos en Cuba}

\section{La industria del diamante.}

En el presente epígrafe, se expondrán los casos obviados por gran parte de los estudios en materia de la presencia hebraica en Cuba. En relación con el caso de la industria del diamante, Robin Truesddale y Judy Kreith (2018), realizadoras del documental "Cuban's forgotten Jewels: a heaven in Havana" ("Joyas cubanas olvidadas: un paraíso en la Habana”), documental exhibido en el cine teatro América, en el marco del Festival de Cine Latinoamericano de La Habana, refieren:

Estábamos fascinadas y sorprendidas de que muy pocas personas en Cuba sabían sobre la industria del diamante que existió en Cuba creada por los refugiados de Amberes en los años 1940 [...] Hoy no existe en la isla evidencia física de esos talleres, ni signos de que esa industria existió (Moreno, 2018).

En efecto, de la industria del diamante creada en Cuba entre 1942 y 1943 por un grupo de refugiados procedentes de Amberes, Bélgica, no ha quedado ningún rastro físico, ni registro histórico apreciable a simple vista, más allá del material fotográfico en publicaciones de la época y en viejos expedientes de archivo (Archivo Nacional de Cuba y Fondo Registro de Asociaciones; L: 1-5). Un ejemplo puede encontrarse en la Figura 5.

Cuando las tropas alemanas invadieron Bélgica el 10 de mayo de 1940, cientos de judíos de Amberes de origen polaco vinculados con el negocio del diamante, buscaron refugio en Cuba, y fueron capaces -literalmente hablando- de traer consigo la industria del diamante, que solo requería de un pequeño equipamiento, más allá de las máquinas cortadoras y pulidoras que posteriormente reprodujeron según prototipo importado de Brasil. Los "belgas" trajeron no solo su experiencia técnica en el negocio, sino los contactos en el mercado internacional. Así establecieron una exitosa industria en tiempos de guerra que les proporcionó un medio de vida nada desdeñable durante su estancia como refugiados, y que constituyó, además, una fuente de empleo para cientos de trabajadores cubanos. Esto último puede ser explicado por la Ley de Nacionalización del Trabajo (Ley del 50 por ciento) instituida en Cuba desde 1933, la cual exigía que la mitad de los trabajadores de toda empresa cubana fueran nativos o nacionalizados cubanos (Bejarano, 1998, p. 6o).

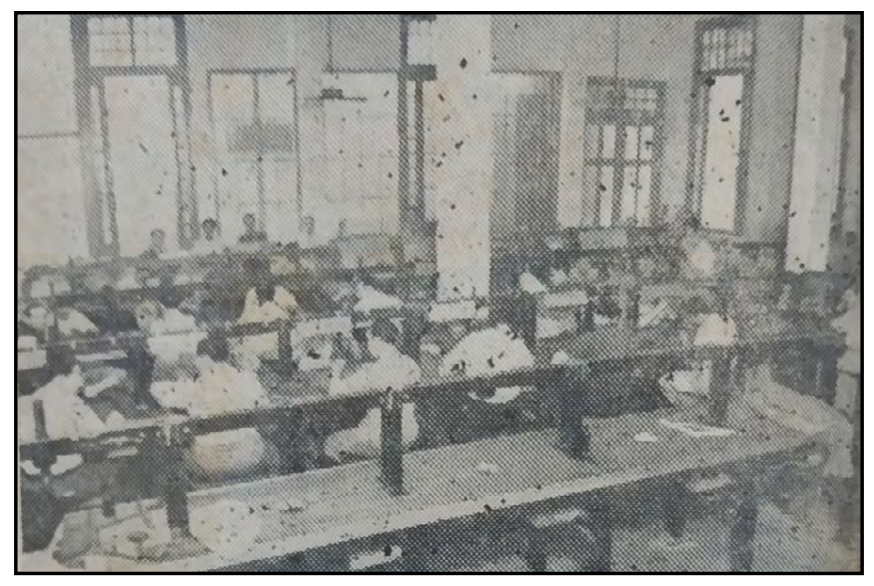

Figura 5. Taller de corte y pulido de diamante. Tomado de Almanaque Hebreo Vida Habanera, La Habana, septiembre de 1943.

En 1944, una publicación hebrea de la época hablaba con orgullo de la existencia en La Habana de alrededor de 26 talleres de corte y pulido de diamante, que empleaban alrededor de 600 refugiados y casi el doble de trabajadores cubanos (Berger, 1944, p. 23). Según la misma fuente, el monto total de las contribuciones de dichas industrias a la economía nacional -por concepto de pago de impuestos, alquiler de locales, piezas de repuesto y pago de jornales- alcanzaba el monto de "siete cifras" (p. 24).

La industria del diamante fundada por los refugiados belgas se justificaba como parte del "esfuerzo de guerra", y aunque el gobierno cubano la permitió y alentó, una vez finalizada la contienda no fue capaz de mantenerla, ya que la mayoría de los refugiados "diamanteros" se trasladaron o bien hacia los Estados Unidos, o bien hacia Israel, o bien se volvieron a Bélgica, llevando consigo sus contactos. Tampoco sobrevivió la práctica del pulido y corte del diamante entre los cubanos que habían sido entrenados.

El documental Cuba's Forgotten Jewels: a heaven in Havana rescata una parte de esta historia olvidada, a partir del testimonio de Marion Finkels Kreith, madre de una de las realizadoras, Judy Kreith. Marion tenía 14 años cuando su familia huyó de la Bélgica ocupada por los nazis hacia Cuba, donde trabajó en la industria del diamante (véase la Figu- 
ra 6). La constante mención de Cuba en sus recuerdos motivó a su hija a acometer esta realización que tiene como centro la vida de los refugiados en Cuba, sus estrategias de supervivencia y de adaptación y su ingenio creador al darle vida a una industria totalmente nueva en el país.

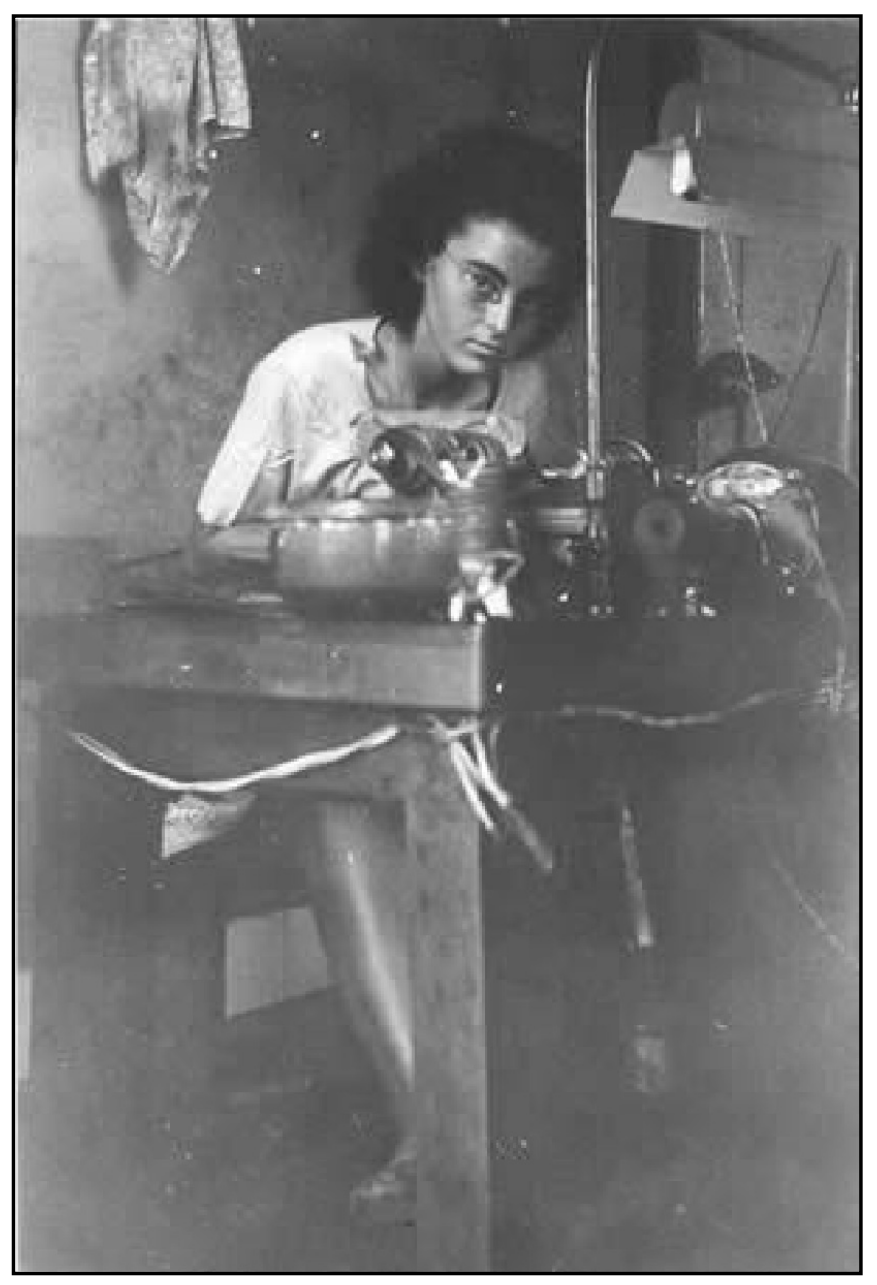

Figura 6. Marion Finkels Kreith tenía 14 años cuando su familia huyó de la Europa ocupada por los nazis hacia Cuba. Ella es la inspiración principal para el documental "Cuba's Forgotten Jewels, a heaven in Havana". (Cortesía de Judy Kreith).

\section{La experiencia interdenominacional de la finca "Paso Seco".}

Aún menos conocida, resulta la experiencia de los judíos refugiados en torno al experimento social de la finca Paso Seco promovido por varias denominaciones religiosas estadounidenses reunidas en el American Friends Service Committee (AFSC), que coordinaron ayudar a los judíos refugiados con las organizaciones filantrópicas hebreas norteamericanas, como el JOINT.

En agosto 1939 los cuáqueros -denominación religiosa cristiana- del AFSC rentaron varias hectáreas de tierra en las afueras de La Habana, en la finca denominada "Paso Seco", ubicada en Calabazar (donde hoy se encuentra el Parque Lenin). La propiedad, contaba con un edificio de dos pisos con alrededor de veintiuna habitaciones, que se constituyó en la sede del Centro Internacional de Entrenamiento Educativo a Refugiados, un programa de atención y entrenamiento con vistas a preparar a los refugiados judíos para su futuro tránsito hacia los Estados Unidos. El programa consistía en la enseñanza y preparación de los refugiados en labores agrícolas, habilidades manuales y diversos oficios sobe la base del trabajo comunal, así como cursos intensivos de idioma inglés y español. Igualmente, los apoyaban emocionalmente para aprovechar saludablemente el tiempo de la obligatoria estadía de tránsito en la Isla.

Entre 1939 y 1940, voluntarios norteamericanos atendieron a alrededor de cincuenta refugiados entre los más necesitados: sobre todos jóvenes y adolescentes que habían perdido a su familia entre los seis millones de vidas cobradas por el genocidio nazi, sin recursos o parientes en los Estados Unidos que los ayudaran. Pero no siempre con el éxito esperado. Impactados por su pasado reciente y totalmente desorientados e inciertos respecto al futuro, muchos refugiados se mostraron totalmente insatisfechos con el experimento: "no valorando la inmensa fortuna de estar a salvo del caos europeo y quejándose porque se sirvieran macarrones en la cena", como expresó Frank A. Rice, uno de los directivos del Centro (Levinson, 2006, p. 142).

Adicionalmente, el programa educativo del Centro de Entrenamiento no tomó en cuenta que trataba de formar colonos y hombres de oficio a individuos que por lo general procedían de grandes ciudades y de un medio social acomodado, los cuales no veían como viables tales esfuerzos, razón por la que muchos decidieron abandonar la finca y volver a La Habana.

Años después, los rastros del Centro Internacional de Entrenamiento para Refugiados han sido buscados por estudiosos e investigadores. En mayo de 2018, la antropóloga y profesora del Colegio Universitario San Gerónimo de La Habana, Dra. Hope Bastian y el norteamericano Steven Baumann, trataron de ubicar el lugar donde se encontraba la antigua granja dirigida por el AFSC en Calabazar y lo que podía quedar del "...edificio de estuco bastante elaborado, [de] dos pisos de altura, techo plano, con un amplio camino que conduce a la entrada del pórtico" (AFSC, 1939, p. 1) que albergó a los refugiados judíos. En el caso de Baumann, él mismo visitó la Isla buscando información sobre la Finca Paso Seco como parte de su proyecto doctoral sobre el 
American Friends Service Committee (AFSC). Gracias a la ayuda de un lugareño que recordaba la finca Paso Seco como una extensa área de cultivo que se encontraba ubicada en lo que es hoy el Parque Lenin (un área de esparcimiento suburbana creada por un programa de la Revolución en 1972 para el recreo de la población habanera) lograron ubicar las "ruinas" de una vieja casona colonial de un antiguo cafetal del siglo XIX, replanteada por el programa de 1972 como el conocido restaurante "La Ruina" (véase la Figura 7), el cual, por su tamaño y ubicación, encaja perfectamente con la descripción de la mansión que la AFSC usó para ayudar a los refugiados judíos (AFSC, 1939, p. 1).

Presumiblemente, el inmueble no solo sirvió de asiento a esclavos y hacendados de los tiempos coloniales, sino a refugiados judíos y voluntarios norteamericanos durante la Segunda Guerra Mundial. Hasta que finalmente sirvió de lugar de esparcimiento a los que buscan un escape ecológico en las afueras de la ciudad, para disfrutar de una "buena comida" en un bello restaurante al estilo colonial.

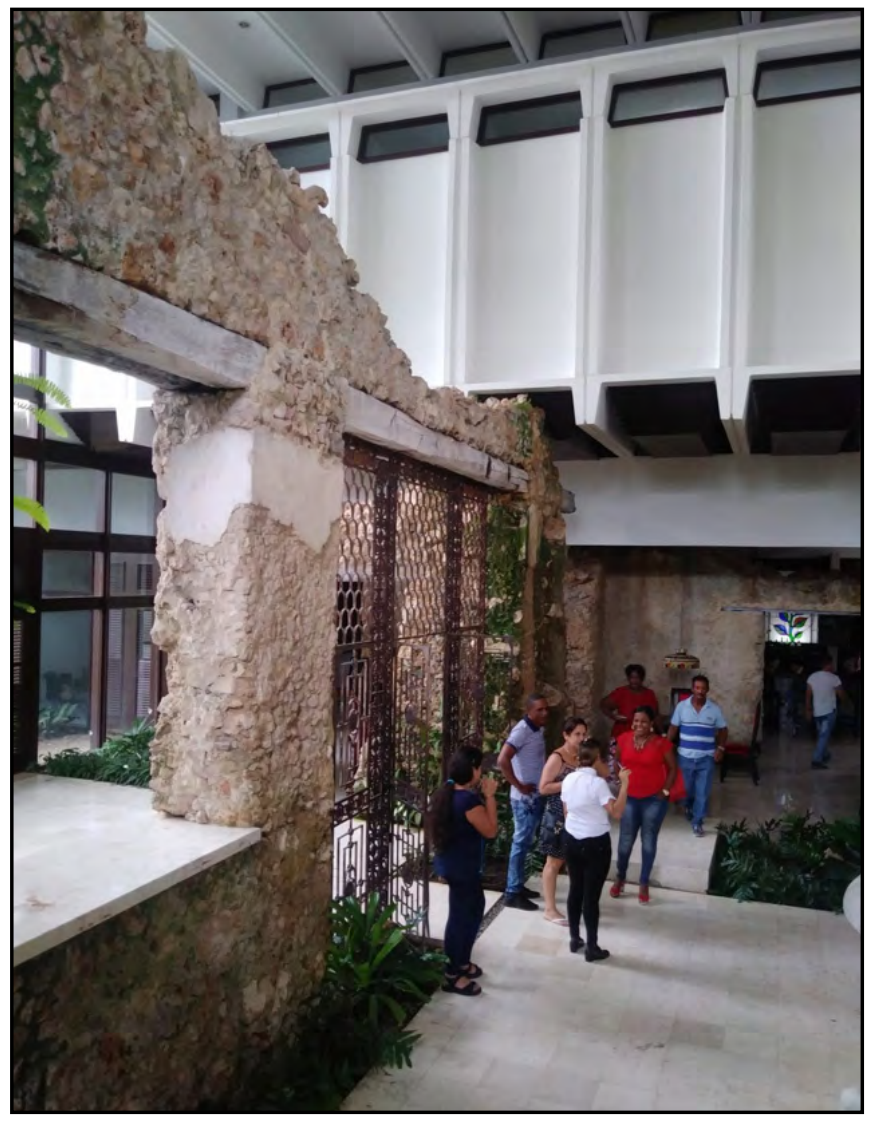

Figura 7. Restaurante "La Ruina" en el parque Lenin, presunto edificio principal del Centro Internacional de Entrenamiento para Refugiados, del programa del AFSC durante los años de la guerra (Cortesía de Hope Bastian).

\section{La huella de los refugiados en el cine cubano.}

Pero quizás el testimonio más conocido, pero menos identificado con el paso de los refugiados judíos por Cuba durante la Segunda Guerra Mundial que devino en huella inmortalizada en el cine cubano, es el caso de Felicia Rosshandler: refugiada alemana que llegó a Cuba junto a su familia en 1942 procedente de Amberes, a donde habían emigrado desde Alemania cuando Hitler ascendió al poder. Felicia no sólo se convirtió en "una teenager cubana”, como ella describe en su libro Passing Through Havana, A Novel of a Wartime Girlhood in the Caribbean (Rosshandler, 1984), sino que encontró el amor durante su refugio en Cuba cuando se enamoró del entonces joven cubano, Edmundo Pérez Desnoes, quien fuera el autor de "Inconsolable Memories” (véase la Figura 8). El guion de esta obra fue llevada al cine -junto con el mismo Desnoes- por Tomás Gutiérrez Alea en 1968 con el nombre de "Memorias del subdesarrollo".

Felicia y su familia migraron a los Estados Unidos en 1948, y en 1980 se reencontró en Nueva York con Edmundo, con quien comparte su vida desde entonces. Ella describe la experiencia de su llegada a la Isla de la siguiente manera:

No se imaginan el choque que representó la llegada a la Habana para una joven venida de la Europa ocupada, como yo; era como pasar del blanco y negro a una vida de colores... había músicos en las calles, turistas americanos, gente vendiendo baratijas y exóticas piñas... era todo colorido y muy vivo..., la Habana era una ciudad maravillosa... el pueblo de Cuba generoso y acogedor (Brockers, 2013).

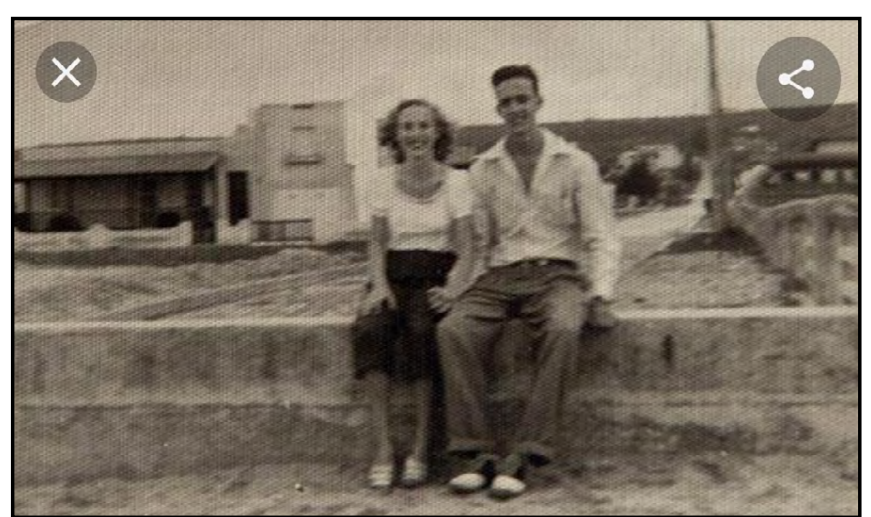

Figura 8. Felicia Rosshandler y Edmundo Pérez Desnoes cuando se conocieron en La Habana siendo aún adolescentes (Recuperada de la web).

El joven Edmundo era hijo de padre cubano y madre jamaicana y ambos se conocieron en una 
fiesta privada en La Habana cuando tenían apenas 15 años. Desnoes escribió en 1965 su libro "Memorias Inconsolables", donde narra la alienación de burgués cubano que decide quedarse en Cuba luego de la partida de su familia y trata de adaptarse a los cambios de la Revolución. En el filme de Gutiérrez Alea, este pone en boca de Sergio -su protagonista(interpretado magistralmente por el actor cubano ya fallecido Sergio Corrieri, según puede apreciarse en la Figura 9) estas palabras: “...la segunda mujer de mi vida vino a Cuba con su familia huyendo de Hitler", refiriéndose a la temprana historia de amor de Desnoes con Felicia, la joven refugiada que inspiró al personaje de Hanna, la joven de rizos rubios de la que Segio (Desnoes) se enamoró cuando tenía 15 años. En otra escena, el niño Sergio espera a Hanna a la puerta de la escuela, salen corriendo a la luz de la tarde y se oye una voz en off que dice: "¿Por qué te dejé ir alguna vez?” (Brockers, 2013). Un retrato de la pareja puede verse en la Figura 10.

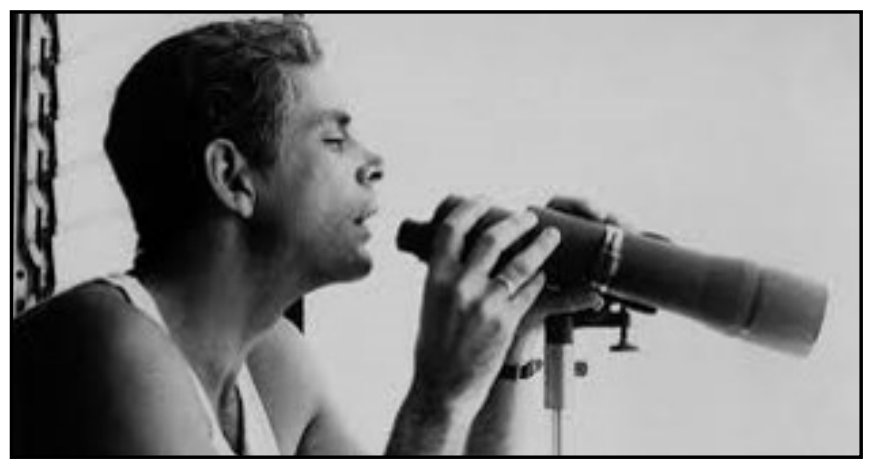

Figura 9. Sergio Corrieri en el filme cubano "Memorias del subdesarrollo", dirigido en 1968 por Tomás Gutiérrez Alea (Titón) basado en la novela "Memorias Inconsolables" (1965), de Edmundo Desnoes.

\section{A manera de epílogo}

Los movimientos migratorios de los judíos, algunos de los cuales fueron comentados durante el desarrollo de las anteriores líneas, constituyen un fenómeno universal acogido durante siglos como rasgo característico de un pueblo empujado a huir de la discriminación y casi siempre de la amenaza de exterminio físico. Salvo específicos eventos como el del buque St. Louis, al que le fue denegado el permiso de desembarco en Cuba en mayo de 1939, fueron muchos los refugiados hebreos que encontraron en Cuba un refugio seguro contra la persecución y la muerte. Borradas o presentes, pero muchas veces olvidadas, las huellas de su paso por la Isla están aún por escribirse. Sirva esta breve reflexión histórica como un primer acercamiento para no repetir otra vez como Sergio, el protagonista de "Memorias del subdesarrollo”: ¿por qué te dejé ir?

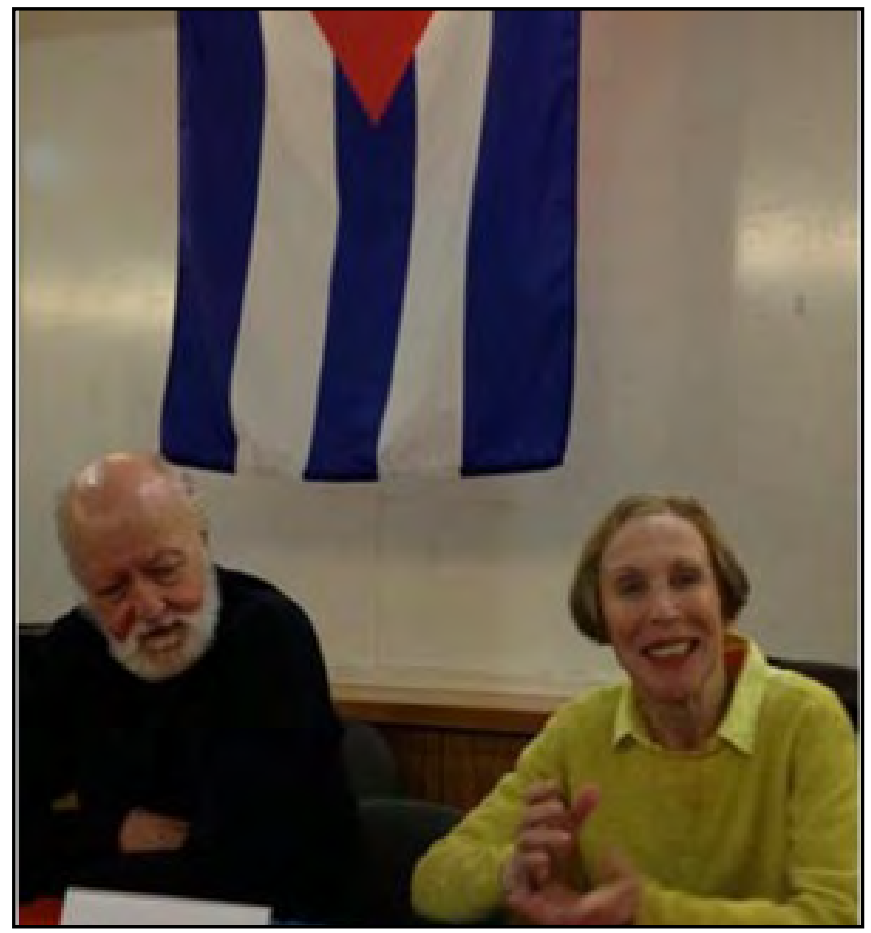

Figura 10. Felicia y Edmundo en la conferencia "Cuba: mito y realidad", en la Universidad Hebrea de Jerusalén, 2013. Tomada de "Bridges to/from Cuba".

\section{Referencias bibliográficas}

Astro, A. (2002). La literatura Yiddish de Cuba. Cuadernos Americanos. Nueva Época. 96(6). Universidad Nacional Autónoma de México, pp. 193- 207. Recuperado de: http://www. cialc.unam.mx/ca/ne/NE-96.pdf

Behar, R. y Blanco, R. (25 de julio de 2013). Con Felicia y Edmundo en Israel [Blog], Bridgest to / from Cuba. Recuperado de: https://www. ruthbehar.com/2013/07/25/with-felicia-andedmundo-in-israel/

Berger, W. (1944). Significación para Cuba de la última corriente migratoria hebrea. Almanaque Hebreo Vida Habanera, La Habana, Cuba: Editorial Vida Habanera, pp. 17- 27.

Bejarano, M. (1988). The deproletarization of Cuban Jewry. Judaica Latinoamericana. Estudios Histórico-Sociales. AMILAT, Editorial Universitaria Magnes, Universidad Hebrea de Jerusalén, pp. 57 - 67. Recuperado de: https:// amilat.online/wp-content/uploads/2019/12/ Margalit-Bejarano-Rosa-57.pdf

Bejarano, M. (1996). La comunidad hebrea de Cuba: la memoria y la historia. Jerusalén: Instituto Abraham Harman de Judaísmo Contemporáneo, Hebrew University of Jerusalem. 
Bejarano, Margalit (1999): La historia del buque San Luis: La perspectiva cubana. Jerusalén: Instituto Abraham Harman de Judaísmo Contemporáneo, Universidad Hebrea de Jerusalén.

Brockers, E. (9 de febrero de 2013). Amor interrumpido: la relación que sobrevivió al nazismo, el comunismo, el exilio y la revolución. The Guardian. Recuperado de: https://www.theguardian.com/ lifeandstyle/2013/feb/o9/enduring-loveaffair-desnoes-rosshandler

Hernández Gómez de Molina, A. (2019a) Sephardi. En: Encyclopedia of Latin American Religions. (1 ed., pp. 1475-1477). Rochester: Springer. https://doi.org/10.1007/978-3-319-27078-4

Hernández Gómez de Molina, A. (2019b) Ashkenazi. En: Encyclopedia of Latin American Religions. (1 ed., pp. 115-118). Rochester: Springer. https://doi.org/10.1007/978-3-31927078-4

Hernández Gómez de Molina, A. (2019 c). ¿Judío o comunista? Una polémica de los 30' en Cuba. Temas Americanistas, 43, Universidad de Sevilla, pp. 217-230. Recuperado de: https:// institucional.us.es/tamericanistas/uploads/ TA-43/o9_HERNANDEZ.pdf

Koehler, M. J. (1943). Los judíos en Cuba. Almanaque Hebreo Vida Habanera. La Habana, Cuba: Editorial Vida Habanera, pp. 11- 14.

Levine, R. M. (1993): Tropical diáspora. The Jewish experience in Cuba. Gensville: University Press of Florida.

Levine, R. M. (2016). Counting Shadows: a Broader Look at Cuban Jewish history. Florida: University of Miami. Recuperado de: http:// www.jewishcuba.org/shadows.html

Levinson, J. (2006): Jewish community of Cuba. The Golden age 1906-1958. Nashville: Wetswiew Publishing Co.

Moreno, S. (11 de enero de 2018). Huyeron de los nazis y crearon una industrial del diamante en Cuba de la que nadie parece saber nada. El Nuevo Herald. Recuperado de: https:// www.elnuevoherald.com/noticias/mundo/ america-latina/cuba-es/article194001149.html

Ortiz, F. (1957). Introducción: La fama póstuma de José Martí. En: Pitchón, M. Martí y la comprensión humana. 1853-1953.

La Habana, pp. 15-30.
Perelmuter, R. (2015). Experiencing Life as a Jew in Cuba in the 1930s [Ponencia]. XXXIII Congreso Internacional de Estudios Latinoamericanos. Latin American Studies Association, LASA, Puerto Rico.

Rosshandler, F. (1984). Passing Through Havana, A Novel of a Wartime Girlhood in the Caribbean. Nueva York: St. Martin's Press.

\section{Referencias documentales}

American Friends Service Committee (AFSC). (3 de noviembre de 1939). Finca Paso Seco. International Work and Language Camp for Refugees in Cuba. Recuperado de: https://www.afsc.org/sites/default/files/ documents/1939\%2oFinca\%2oPaso\%20 Seco\%20-\%2oRefugees\%20-\%2oCuba.pdf

Archivo Nacional de Cuba y Fondo Registro de Asociaciones. Asociación de Industriales del Diamante en Cuba. Número de orden (No): 0046o9, Legajo (L): 1-5.

Archivo Nacional de Cuba y Fondo Registro de Asociaciones. Unión de Refugiados Hebreos. L: 350; Ex.: 444.

Matterin, A. M. (1969). Historia de los hebreos en Cuba (Desde el descubrimiento hasta 1969) [Mecanuscrito inédito]. Archivo Histórico de la Oficina del Historiador de la Ciudad de La Habana (AH- OHC); F: Abraham Marcus Matterin; L: 269.

\section{Audiovisuales}

Kreith, J. y Truesdale, R. (Realizadores). (2018). Cuban's forgotten jewels: a haven in Havana [Documental]. Forgotten Jewels Film, Two Hands Films.

\section{Notas}

1 Los "belgas" en realidad eran judíos de origen polaco, que se habían establecido en Amberes. NA.1 Sería impreciso asegurar el origen tácito de un género musical tan híbrido como el reguetón y se conoce que existe una disputa entre las naciones de Puerto Rico y Panamá por adjudicarse la creación del género. 